\title{
Corrosion Resistance of Carbon Steel Immersed in Simulated Concrete Pore Solution in the Presence of Amino Benzoic Acid
}

\author{
S. Karthikeyan, S.S. Syed Abuthahir* and M. Mohammed Aatham \\ Department of Chemistry, Jamal Mohamed College (Autonomous), Affiliated \\ to Bharathidasan University, Tiruchirappalli- 620 020, Tamilnadu, India \\ Corresponding author email: syedchem05@gmail.com
}

\begin{abstract}
Concrete is used in construction of buildings. Simulated concrete pore solution (SCPS) is equivalent to concrete admixtures. The corrosion resistance of carbon steel immersed in simulated concrete pore solution prepared in well water, in the absence and presence of amino benzoic acid. Corrosion resistance has been evaluated by the weight loss method. The mechanistic aspects of corrosion inhibition have been studied by electro chemical studies such as Polarisation study and AC impedance spectra. It is observed that when amino benzoic acid is added to SCPS, the corrosion resistance increases. As the concentration of amino benazoic acid increases corrosion resistance also increases. This is confirmed by electrochemical studies. When corrosion resistance increases, charge transfer value $(\mathrm{Rt})$ increases, impedance value $(\log (\mathrm{Z} / \Omega)$ increases, and double layer capacitance $(\mathrm{Cdl})$ decreases. The present study leads to the conclusion that the addition of amino benzoic acid to concrete admixtures will increase the corrosion resistance of carbon steel which can be used as rebars. The formation of protective film on the carbon steel has been characterized by FTIR spectra. The smoothness of surface film over the mild steel surface has been analyzed by scanning electron microscopy.
\end{abstract}

KEY WORDS: AMINO BENZOIC ACID, CARBON STEEL, CONCRETE CORROSION, FT-IR, SIMULATED CONCRETE PORE SOLUTION, SEM.

\section{INTRODUCTION}

Reinforced concrete is widely used for building materials and plays a significant role in economic development. The premature degradation of reinforced concrete structures due to the reinforcing steel corrosion has resulted in a huge economic loss in modern society. That's why; the study on the corrosion behavior of the reinforcing steel is of great practical significance. Under normal conditions, reinforcing steel in concrete can be protected from corrosion by simultaneously forming a compact passive film on the steel surface because of the high alkalinity of the concrete

Biosc Biotech Res Comm P-ISSN: 0974-6455 E-ISSN: 2321-4007

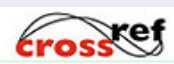

Identifiers and Pagination

Year: 2021 Vol: 14 No (7) Special Issue

Pages: 481-488

This is an open access article under Creative

DOI: $h t t p: / / d x . d o i . o r g / 10.21786 / b b r c / 14.7 .99$
Commons License Attribn 4.0 Intl (CC-BY). pore solution. The long time necessary for chlorides to penetrate the concrete cover can be avoided by testing the steel in concrete simulated pore solution, which is mainly consisted of saturated calcium hydroxide $(\mathrm{Ca}(\mathrm{OH}) 2)$, sodium hydroxide $(\mathrm{NaOH})$ and potassium hydroxide $(\mathrm{KOH})$ (Kumar, 1998; Pandiarajan, 2013; Pandiarajan et al., 2013; Yang et al., 2021).

However, in numerous studies of rebar corrosion, saturated $\mathrm{Ca}(\mathrm{OH}) 2$ has been used as a substitute for pore solution. Furthermore, the other ions present in pore solution, particularly, sodium and potassium may also play a role in mechanism of $\mathrm{Cl}$ - inducing the steel depassivation and the critical concentration for the steel corrosion has attracted considerable attention of corrosion researchers. Due to the differences in experimental systems and measurements methods etc., the measurement results of the critical chloride concentrations differed greatly. Simulated concrete pore solutions are commonly used for studying the reinforcing steel corrosion behavior on account of the complexity of the passivation and corrosion processes. The study on the

\section{Article Information}

Received: $10^{\text {th }}$ Aug 2021

Accepted after revision: $14^{\text {th }}$ Oct 2021 
reinforced concrete systems, which is of beneficial help for understanding the corrosion mechanism of reinforcing steel (Poursaee et al., 2010; Guo et al., 2013; Zomorodian et al., 2021).

Several research papers have been investigated the corrosion behavior of metals in presence of simulated concrete pore solution. Usually, rebars have been used in such studies. The present study is undertaken to investigate the corrosion resistance of carbon steel immersed in simulated concrete pore solution prepared in well water in the presence of neem extract. The corrosion inhibition efficiency was evaluated using the weight loss method. Electrochemical studies such as polarization study and $\mathrm{AC}$ impedance spectra have been used to evaluate the corrosion resistance of the materials under investigation. The formation of the surface film on the carbon steel has been characterized by FTIR spectra. The smoothness of surface protective film over the mild steel surface has been analyzed by scanning electron microscopy (Pandiarajan et al., 2012; Zomorodian et al., 2021).

\section{MATERIAL AND METHODS}

The carbon steel specimen was choosen from the same of the following composition: Carbon-phosphorus $0.1 \%$, sulphur $0.025 \%$, manganese $0.4 \%$ and the rest iron. Carbon steel specimen of the dimension $1.0 \times 4.0 \times 0.2 \mathrm{~cm}$ were polished to mirror finish, and degreased with trichloroethylene and used for weight - loss and surface examination studies. Carbon steel rod encapsulated in Teflon with an exposed cross section of $1 \mathrm{~cm}$ area was used as the working electrode in potentiodynamic polarization studies. The surface of the electrode was polished to a mirror finish and degreased with trichloroethylene Muralidran et al., (1996).

Double distilled water was used wherever necessary in the preparation of solutions. Analytical grade $\mathrm{Ca}(\mathrm{OH}) 2$ is taken as such and they were diluted to the required concentration. The required concentration of the Amino benzoic acid stock solution was prepared by dissolving Amino benziocacid in minimum amount of ethanol and making up to the desired volume with double distilled water. Then the required volume from the inhibitor stock solution was added to the calcium hydroxide solution to obtain the desired concentration Jamal et al., (2007).

The Amino benziocacid was used as a corrosion inhibitor. The corrosion inhibition efficiencies of the inhibitor were evaluated by the following methods. Weight loss measurements were done according to the described method Jamal (2005), Syed (2014). Weight loss measurements were performed for $12 \mathrm{hrs}$ by immersing the carbon steel specimens in aqueous solution containing SCP without and with various amounts of Amino benziocacid (50 ppm $-250 \mathrm{ppm}$ ). After elapsed time, the specimen was taken out, washed, dried and weighed accurately. The inhibition efficiency (IE \%) was determined by the following equation.

$\operatorname{IE}(\%)=\frac{\mathrm{Wo}-\mathrm{W} 1}{\mathrm{Wo}} \times 100$
Where W1 and Wo are the weight loss values in $\mathrm{g}$ in the presence and absence of 4-amino benzoicacid respectively. The length, breadth and thickness of carbon steel and the radius of the holes were determined with the help of vernier calipers of high precision and the surface areas of the specimens were calculated.

Weighing the specimens before and after corrosion: The weights of the specimens before and after immersion were determined using a balance, Shimadzu AY 62 model. Determination of corrosion rate: The weighed carbon steel specimens in triplicate were suspended using glass hooks in $100 \mathrm{ml}$ of aqueous solution SCP containing various concentrations of the Amino benziocacid in the presence and absence for one day of immersion. After one day immersion, the specimens were taken out, washed in running water, dried and weighed Syed et al., (2014). From the change in weights of the specimen, corrosion rates were calculated using the following relationship.

$$
\text { Corrosion rate }=\frac{\text { Loss in weight }(\mathrm{mg})}{\text { Surface area of the Specimen }\left(\mathrm{dm}^{2}\right) \times \text { Period of Immersion (days) }} \text { mdd }
$$

Corrosion inhibition efficiency (IE) was then calculated using the equation

$$
\mathrm{I} . \mathrm{E}=100[1-(\mathrm{W} 2 / \mathrm{W} 1)] \%
$$

Polarization studies were carried out in an $\mathrm{H} \& \mathrm{CH}$ electrochemical work station impedance analyzer model CHI660A, Austin, USA, three-electrode cell assembly was used Pandiarajan (2013) Syed (2016). The working electrode was mild steel with one face of the electrode of constant $1 \mathrm{~cm} 2$ area exposed and the rest being shield with red lacquer. A saturated calomel electrode (SCE) was used as the reference electrode and a rectangular platinum foil was used as the counter electrode.

The area of the counter electrode was much larger when compared to the area of the working electrode. This can exert a uniform potential field on the counter electrode. The working electrode and platinum electrode were immersed in an aqueous solution containing SCP in the absence and presence of an inhibitor. A saturated calomel electrode was connected with the test solution through a salt bridge. Potential (E) Vs log current (I) plots were recorded. The results such as corrosion potential (Ecorr) and Icorr Tafel slopes ba, bc were determined from E Vs $\log$ I plots.

AC impedance studies were carried out in an $\mathrm{H} \& \mathrm{CH}$ electrochemical workstation impedance analyzer model CHI660A, Austin, USA, Nagalakshmi (2012), Gowri (2014). The cell setup was the same as that used for polarization measurements. A time interval of 5 to 10 minutes was given for the system to attain a steady state open circuit potential. Then over this steady state potential, an A.C. potential of $10 \mathrm{mV}$ was superimposed. The AC frequency was varied from $100 \mathrm{KHz}$ to $100 \mathrm{MHz}$ the real part (z') and imaginary part (z') of the cell impedance were measured in ohms for various frequencies. The Rt (charge 
transfer resistance) and Cdl (double layer capacitance) values were calculated. Cdl values were calculated using the following relationship.

$$
\mathrm{C}_{\mathrm{dl}}=\frac{1}{2 \times 3.14 \times \mathrm{R}_{\mathrm{t}} \times \mathrm{f}_{\max }}
$$

FTIR spectra were recorded in a Perkin Elmer Spectrum Version spectrophotometer. The film was carefully removed, mixed thoroughly with $\mathrm{KBr}$ made into pellets and the FTIR spectra were recorded. After an immersion period of one day in various environments, the specimens were taken out of the test solutions and dried. The film formed on the surface was scratched carefully and it was thoroughly mixed to make it uniform throughout. FTIR spectrum of the powder ( $\mathrm{KBr}$ pellet) was recorded using a Perkin Elmer Spectrum Version spectrophotometer (Rajammal, 2004; Rajendran, 2005; Sahayaraja, 2012; Agiladevi, 2013).

Table 1. Corrosion rates (CR) of carbon steel immersed in an aqueous solution containing SCP

\begin{tabular}{|l|c|c|c|}
\hline $\begin{array}{l}\text { SCP } \\
(\mathbf{p p m})\end{array}$ & $\begin{array}{c}\text { Amino benzoicacid } \\
\text { (ppm) }\end{array}$ & $\begin{array}{c}\mathbf{C R} \\
\text { (mdd) }\end{array}$ & $\begin{array}{c}\text { IE } \\
\mathbf{( \% )}\end{array}$ \\
\hline 60 & 50 & 29.49 & 55.97 \\
\hline 60 & 100 & 33.25 & 62.26 \\
\hline 60 & 150 & 39.68 & 74.84 \\
\hline 60 & 200 & 46.65 & 87.42 \\
\hline 60 & 250 & 49.87 & 93.71 \\
\hline
\end{tabular}

The mild steel specimen was immersed in blank and in the inhibitor solution for one day was removed, rinsed with double distilled water, dried and observed in a scanning electron microscope to examine the surface morphology. The surface morphology measurements of the mild steel was examined using Tescan, Vega 3, USA computer controlled scanning electron microscope (Sathiyabama, 2009; Shyamala, 2012).

\section{RESULTS AND DISCUSSION}

Corrosion behavior of galvanized iron in simulated concrete pore solution in the presence of neem extract has been investigated by the weight loss method and AC impedance spectra. The corrosion rates (CR) of carbon steel immersed in an aqueous solution containing SCP and also inhibition efficiencies (IE) in the absence and presence of Amino benziocacid obtained by weight loss method are given in table 1 . It is observed that $250 \mathrm{ppm}$ of Amino benziocacid offers $93.71 \%$ of inhibition efficiency. It is observed from Table 1 that Amino benziocacid shows some inhibition efficiency. As the concentration of Amino benziocacid increases, the IE increases. This is due to an increase of surface coverage at higher concentrations of the Amino benziocacid which retards dissolution of carbon steel (Rajendran, 2009; Zomorodian et al., 2021; Tiwari et al., 2021; Yang et al., 2021).

Table.1. Corrosion rates (CR) of carbon steel immersed in an aqueous solution containing SCP in the presence and absence of Amino benziocacid systems at various concentrations and the inhibition efficiency (IE \%) obtained by weight loss method.

- Inhibitor System: Amino benziocacid (250 ppm)

- Immersion period: 1 day

- $\mathrm{pH}=6.5$

Table 2. Corrosion parameters of carbon steel in an aqueous solution containing SCP in the absence and presence of Amino benziocacid system obtained by potentiodynamic polarization method.

\begin{tabular}{|l|c|c|c|c|c|}
\hline Systems & $\begin{array}{c}\text { Ecorr } \\
\mathbf{v s} \\
\text { SCE }(\mathbf{m V})\end{array}$ & $\begin{array}{c}\text { Icorr } \\
(\mathbf{A} / \mathbf{c m})\end{array}$ & $\begin{array}{c}\text { ba } \\
(\mathbf{m V} / \mathbf{d e c})\end{array}$ & $\begin{array}{c}\text { bc } \\
(\mathbf{m V} / \mathbf{e c})\end{array}$ & $\begin{array}{c}\text { LPR } \\
(\mathbf{o h m c m})\end{array}$ \\
\hline $\begin{array}{l}\text { SCP } \\
\text { SCP }+250 \mathrm{ppm}\end{array}$ & -0.655 & $4.889 \times 10-5$ & 0.116 & 0.352 & 778 \\
\hline Amino benziocacid & -0.631 & $2.848 \times 10-5$ & 0.101 & 0.298 & 1154 \\
\hline
\end{tabular}

Analysis of results of potentiodynamic polarization study: A polarization study has been used to confirm the formation of protective film on the carbon steel surface during the corrosion inhibition process. If a protective film is formed on the carbon steel surface, the linear polarization resistance values (LPR) increases and the corrosion current value (Icorr) decreases and corrosion potential increases (Ecorr) (Rajendran, 2002; Rajendran, 2003; Rajendran; 2005; Behpour, 2008).
The potentiodynamic polarization curves of carbon steel immersed in an aqueous solution containing SCP in the absence and presence of Amino benziocacid are shown in Fig $1(\mathrm{a} \& \mathrm{~b})$. The corrosion parameters are given in Table 2. When carbon steel was immersed in an aqueous solution containing SCP the corrosion potential was -0.655 $\mathrm{mV}$ vs SCE. When Amino benziocacid (250 ppm) was added to the above system, the corrosion potential shifted to the positive side $-0.631 \mathrm{mV}$ vs SCE. This indicates that 
the protective film is formed on the anodic sites of the carbon steel surface. This film controls the anodic reaction of carbon steel dissolution by forming a complex on the anodic sites of the carbon steel surface (Zomorodian et al., 2021).

Further, the LPR value increases from $778 \mathrm{ohm} \mathrm{cm}^{2}$ to $1154 \mathrm{ohm} \mathrm{cm}^{2}$, the corrosion current decreases from $2.848 \times 10^{-5} \mathrm{~A} / \mathrm{cm}^{2}$ to $4.889 \times 10^{-5} \mathrm{~A} / \mathrm{cm}^{2}$. Thus polarization study confirms the formation of a protective film on the carbon steel surface.

\section{Polarization curves of carbon steel immersed in test solution}

Figure 1a: Aqueous solution containing SCP

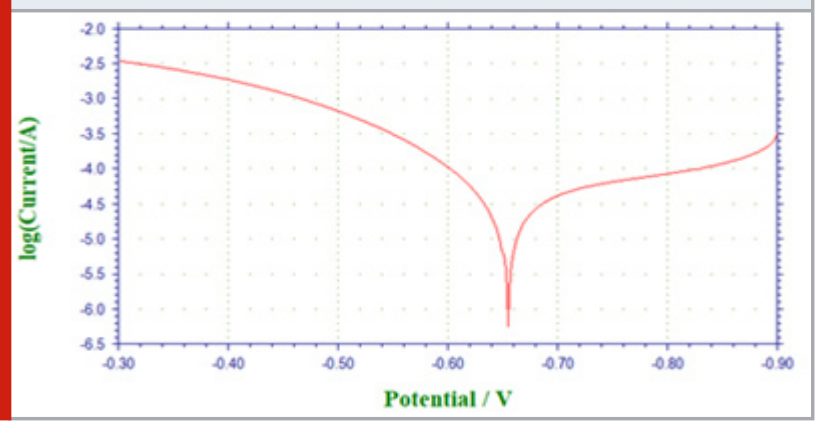

Figure 1b: The aqueous solution containing SCP + Amino benziocacid $(250 \mathrm{ppm})$

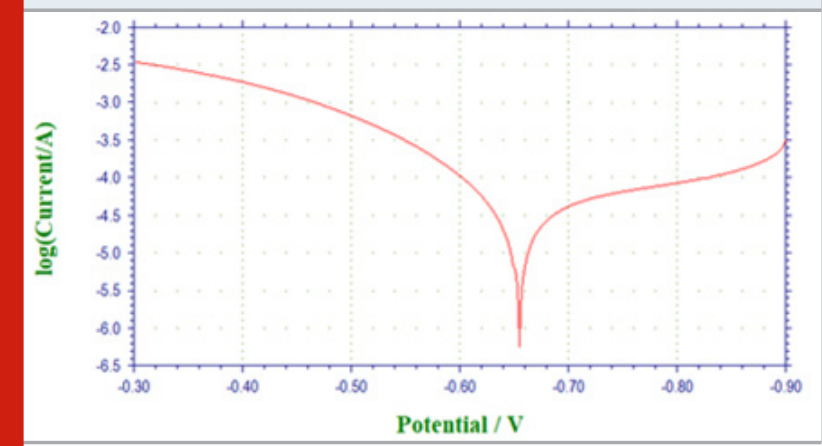

AC impedance spectra (electrochemical impedance spectra) have been used to confirm the formation of protective film on the carbon steel surface. If a protective film is formed on the carbon steel surface, charge transfer resistance $(\mathrm{Rt})$ increases; double layer capacitance value (Cdl) increases and the impedance $\log (\mathrm{z} / \mathrm{ohm})$ value increases (Sekine, 1986; Rajendran, 1996; Rajendran, 2005; Jayasundari, 2013; Zomorodian et al., 2021).

The AC impedance spectra of carbon steel immersed in an aqueous solution containing SCP in the absence and presence of Amino benziocacid are shown in Fig 2 (a \& b) (Nyquist plots) and Figs 3(a \& b) (Bode plot). The AC impedance parameters namely charge transfer resistance (Rt) and double layer capacitance (Cdl) derived from Nyquist plots are given in Table 3. It is observed that when the Amino benziocacid ( $250 \mathrm{ppm}$ Amino benziocacid) is added, the charge transfer resistance $(\mathrm{Rt})$ increases from
$26.59 \Omega \mathrm{cm}^{2}$ to $26.74 \Omega \mathrm{cm}^{2}$. The $\mathrm{Cdl}$ value increases from $43.7937 \times 10^{-6} \mathrm{~F} \mathrm{~cm}^{-2}$ to $44.0407 \times 10^{-6} \mathrm{~F} \mathrm{~cm}^{-2}$. The impedance value $[\log (\mathrm{z} / \mathrm{ohm})]$ increases from 0.500 to 0.521 . These results lead to the conclusion that a protective film is formed on the carbon steel surface. Further, the phase angle increases from 26 to $29^{\circ}$.

Table 3. Corrosion parameters of carbon steel immersed in an aqueous solution containing SCP in the absence and presence of Amino benziocacid system obtained from AC impedance spectra.

\begin{tabular}{|c|c|c|c|}
\hline \multirow[t]{2}{*}{ Systems } & \multicolumn{2}{|c|}{ Nyquist plot } & \multirow{2}{*}{$\begin{array}{c}\text { Bode plot } \\
\text { Impedance } \\
\operatorname{Lg}\left(\mathbf{Z} \text { ohm }^{-1}\right)\end{array}$} \\
\hline & $\begin{array}{c}\text { Rt } \\
\Omega \mathrm{cm}^{2}\end{array}$ & $\begin{array}{c}\text { Cdl } \\
\mathrm{F} \mathrm{cm}^{-2}\end{array}$ & \\
\hline SCP & 26.59 & $43.7937 \times 10^{-6}$ & 0.500 \\
\hline $\begin{array}{l}\mathrm{SCP}+250 \mathrm{ppm} \\
\text { Amino } \\
\text { benziocacid }\end{array}$ & 26.74 & $44.0407 \times 10^{-6}$ & 0.521 \\
\hline
\end{tabular}

\section{Nyquist plot (Blank)}

Figure 2a: AC impedance spectra (Nyquist plots) of carbon steel immersed in various test solutions - Aqueous solution containing SCP.

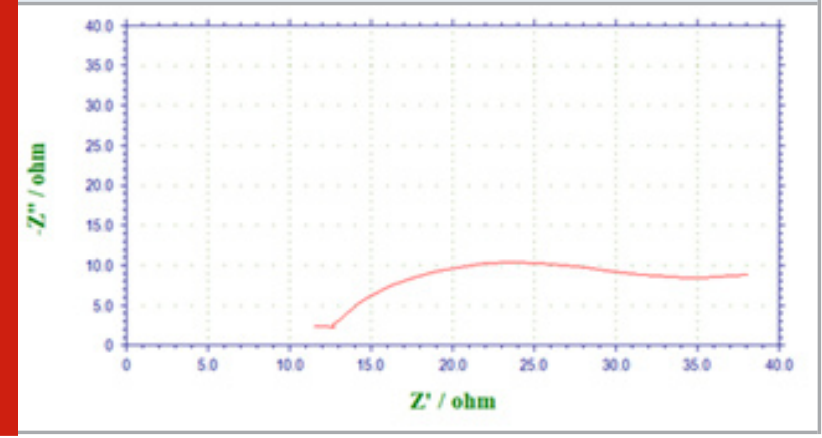

Figure 2b: The aqueous solution containing $\mathrm{SCP}+250 \mathrm{ppm}$ Amino benziocacid

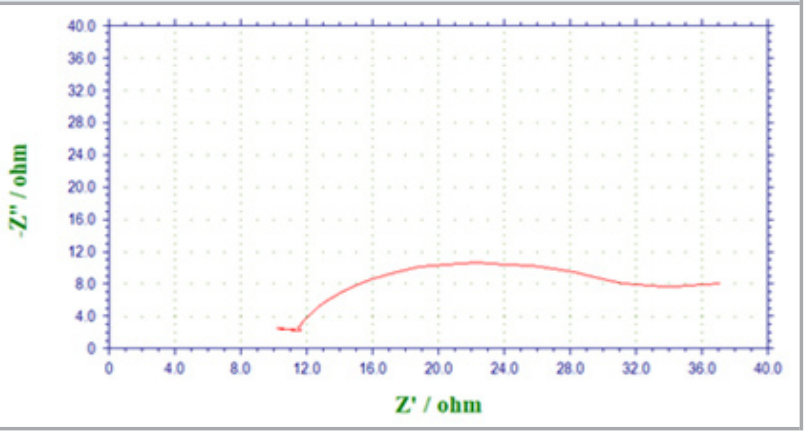

FTIR spectra have been used to analyze the protective film formed over on the carbon steel surface Silvestein et. al. (1981). The structure of amino benzoic acid is shown 1. The FTIR spectrum $(\mathrm{KBr})$ of pure amino benzoic acid is shown in Fig.5a. The $\mathrm{CH}$ stretching frequency appears at $2918.60 \mathrm{~cm}^{-1}$. The $\mathrm{CO}$ stretching frequency appears at $1626.32 \mathrm{~cm}^{-1}$. 
SEM provides a pictorial representation of the surface of the carbon steel. To understand the nature of the surface film in the absence and presence of inhibitor and the extent of corrosion of carbon steel, the SEM micrographs of the surface are examined Ikhmal (2020), Yousif (2016). The SEM images of carbon steel specimen immersed in an aqueous solution containing SCP $+250 \mathrm{ppm}$ of amino benzoic acid for 3 hours in the absence and presence of inhibitor system are shown in Fig.6 ( $a, b$ and c) respectively.

Figure 3a: AC impedance spectra (Bode Plot) of carbon steel immersed in an aqueous solution containing SCP

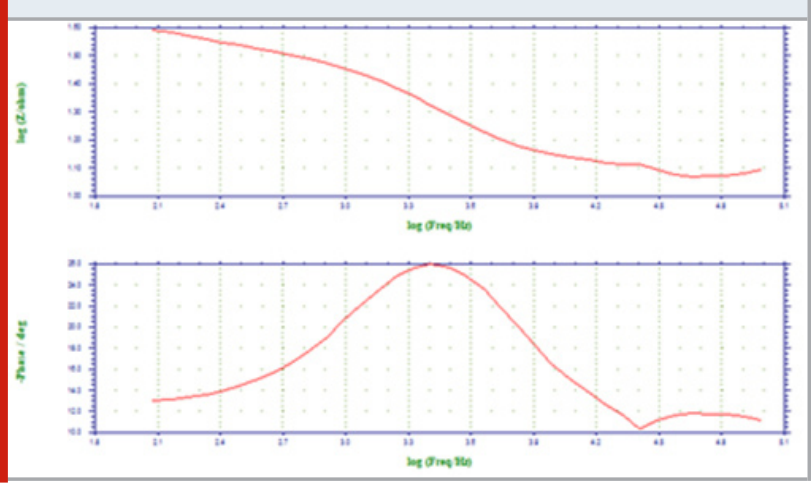

Figure 3b: AC impedance spectra (Bode Plot) of carbon steel immersed in an aqueous solution containing SCP + 250 ppm of Amino benziocacid

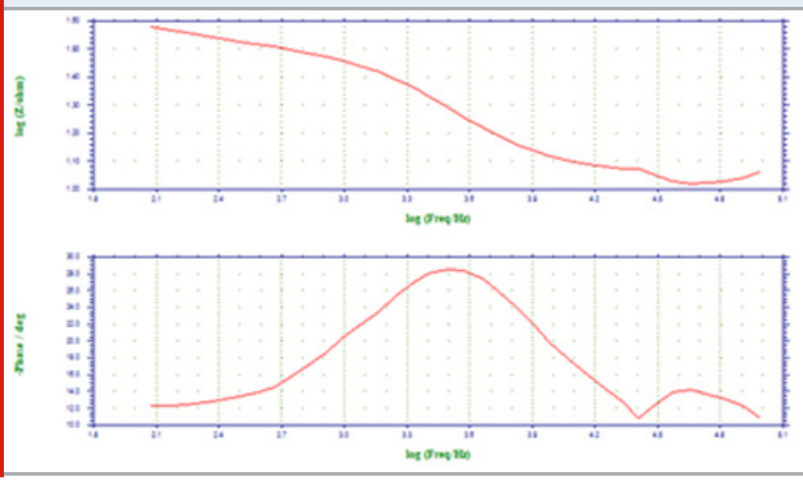

Figure 4a: Phase angle of carbon steel immersed in an aqueous solution containing SCP

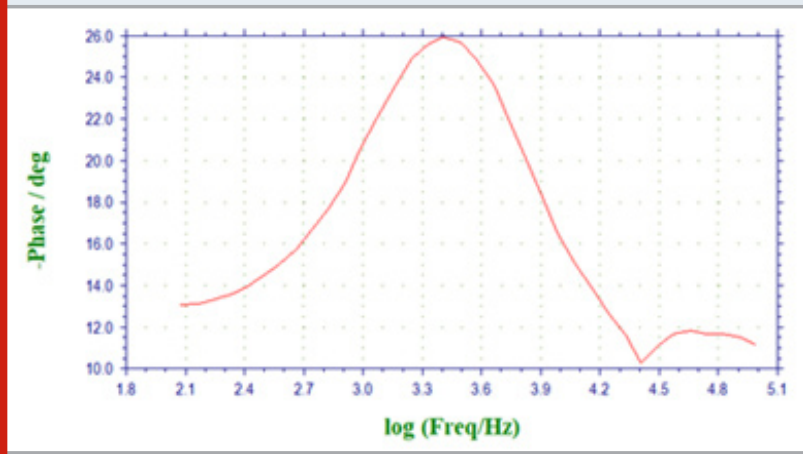

The SEM micrograph of polished carbon steel surface figure shows a smooth surface, there are no corrosion or
Figure 4b: The phase angle of carbon steel immersed in an aqueous solution containing $\mathrm{SCP}+250 \mathrm{ppm}$ of Amino benziocacid

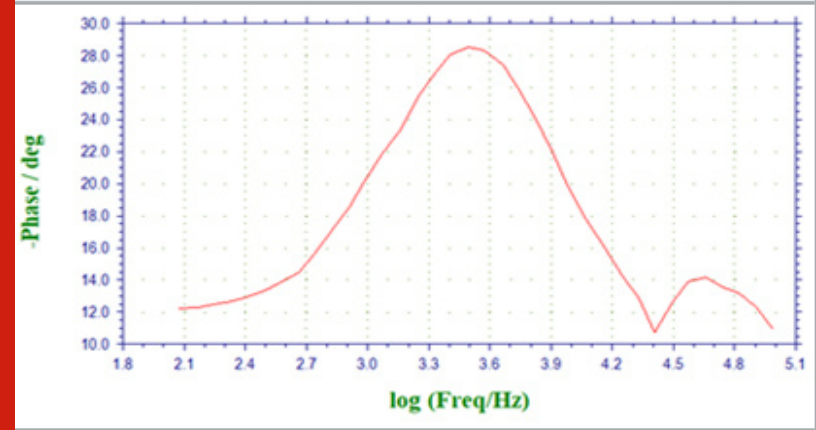

Scheme 1: Structure of Amino benzoic acid

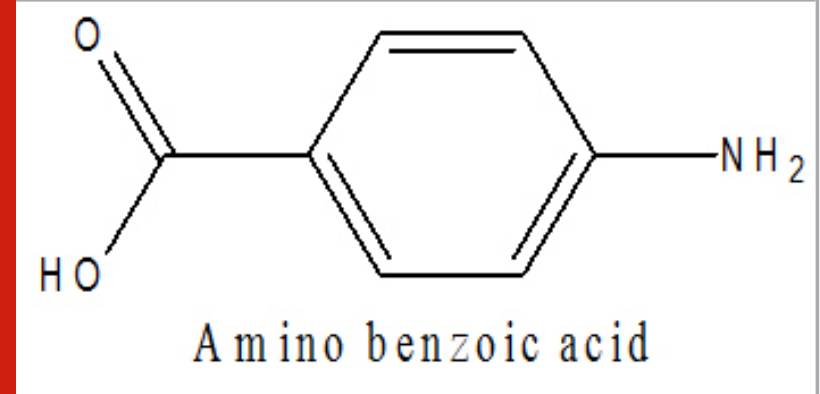

Table 4. IR values of pure benzimidazole and film formed over the carbon steel surface is obtained from IR Spectra.

\begin{tabular}{|l|c|c|}
\hline $\begin{array}{l}\text { Functional } \\
\text { Group }\end{array}$ & $\begin{array}{c}\text { Pure Amino } \\
\text { benzoic acid } \\
\text { Compound } \\
\text { (Peak Appears } \\
\text { at } \mathbf{c m}^{-1} \text { ) }\end{array}$ & $\begin{array}{c}\text { The Protective film } \\
\text { consists of } \mathbf{F e}^{\mathbf{2}}- \\
\text { Amino benzoic acid } \\
\text { (Peak Appears at } \mathbf{c m}^{-1} \text { ) }\end{array}$ \\
\hline CH & 2918.60 & 2923.38 \\
\hline CO & 1626.32 & 1630.88 \\
\hline OH & 3461.52 & 3429.48 \\
\hline NH & 3363.49 & - \\
\hline MO & - & 620.76 \\
\hline
\end{tabular}

corrosion products. The SEM micrograph of carbon steel surface immersed in an aqueous solution of SCP Fig.(b) show the roughness of the carbon steel surface which indicates the highly corroded area of carbon steel in an aqueous solution containing SCP. However in Fig.8 (c) carbon steel in an aqueous solution of SCP with $250 \mathrm{ppm}$ of amino benzoic acid, indicate that in the presence of inhibitor, the rate of corrosion is suppressed, as can be seen from the decrease of corroded areas. The carbon steel surface is almost free from corrosion due to the formation of the insoluble complex on the surface of the carbon steel. In the presence of amino benzoic acid, the surface is covered by a thin layer of inhibitor which effectively controls the dissolution of carbon steel (Zomorodian et al., 2021). 
Figure 5a: FTIR spectrum of pure Amino benzoic acid

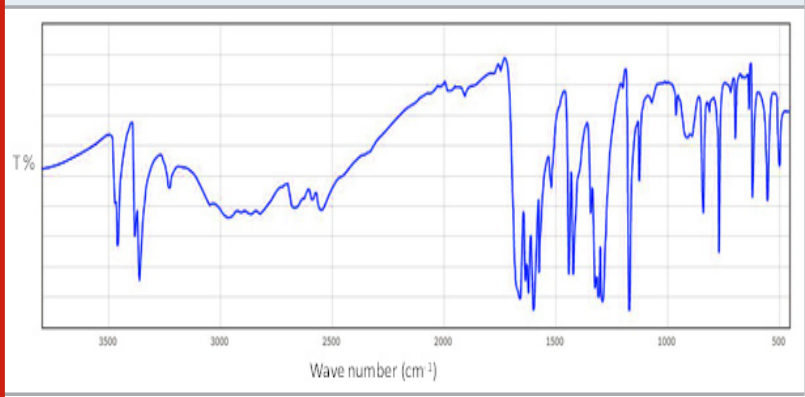

Figure 5b: FTIR spectrum of the film formed on the carbon steel surface after immersion in SCP and 250ppm of Amino benzoic acid inhibitor

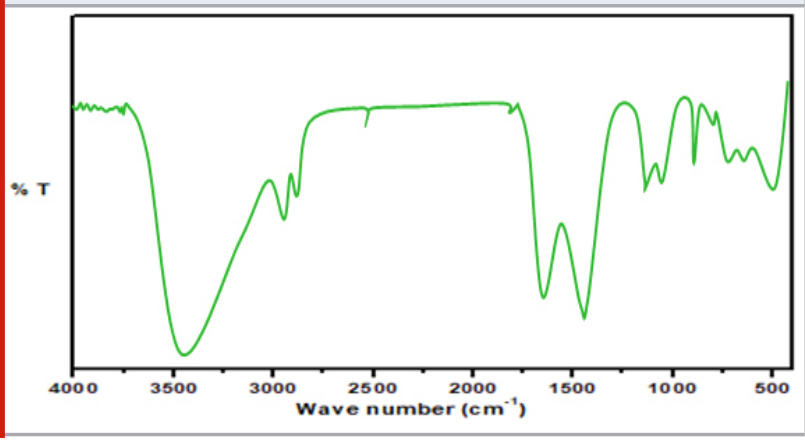

Figure 6a: SEM images of polished carbon steel surface (control)

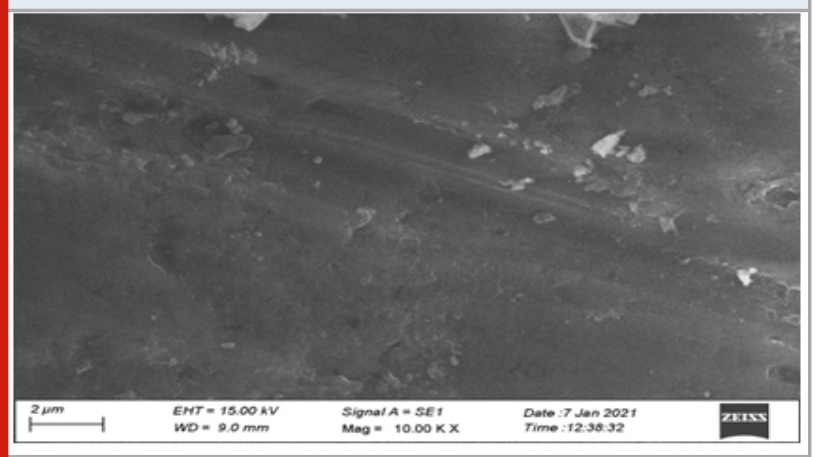

Figure 6a: SEM images of polished carbon steel surface immersed in SCP solution (blank)

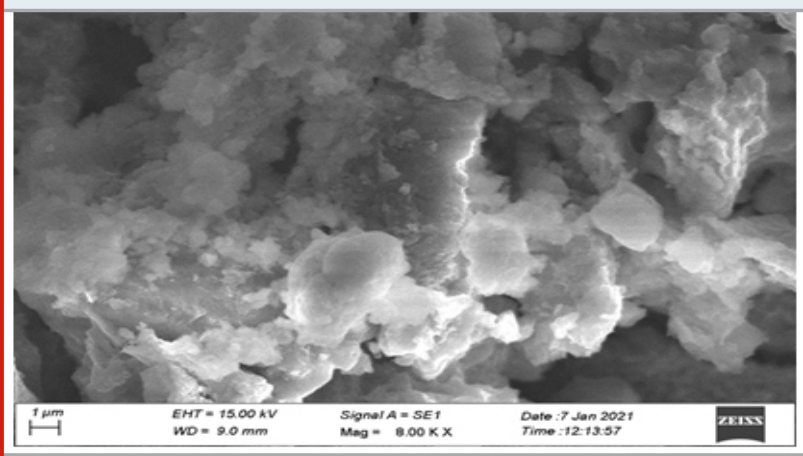

Figure 6c: SEM images of polished carbon steel surface immersed in SCP with 250 ppm of amino benzoic acid.

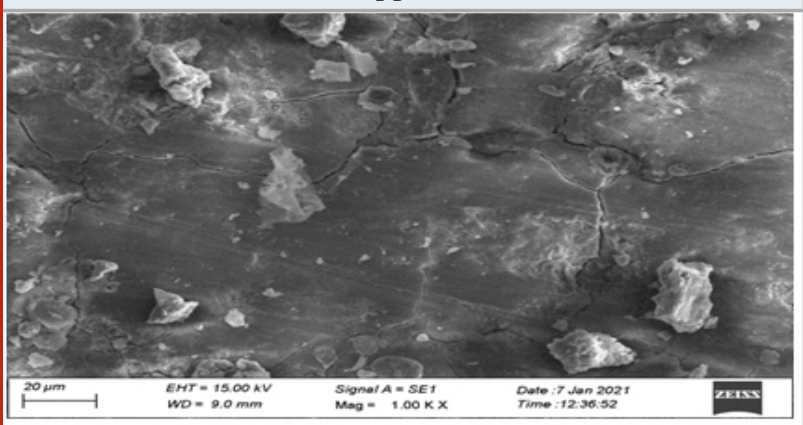

It is well known that organic molecules which as Amino benzoic acid carry their inhibition action via the adsorption on the carbon steel surface. The adsorption process depends on the chemical structure of the inhibitor, the nature and charged surface of the metal and the distribution of charge over the whole inhibitor molecule. In general, owing to the complex nature of adsorption and inhibition action of Amino benzoic acid, it is impossible for a single adsorption mode between Amino benzoic acid and carbon steel surface.

Organic inhibitor molecules may be adsorbed on the carbon steel surface in one or more of the following ways: a) Electrostatic interaction between the charged molecules and the charged carbon steel, b) Interaction of unshared electron pairs in the molecule with the carbon steel, c) Interaction of $\pi$-electrons with the carbon steel.

Generally, Heteroatom of inhibitor may be adsorbed on the surface of carbon steel through the chemisorptions mechanism, involving the displacement of water molecules from the carbon steel surface and the sharing electrons between the hetero-atoms and iron. The Amino benzoic acid molecules can also adsorb on the carbon steel surface based on donor-acceptor interactions between $\pi$-electrons of the heterocyclic ring and vacant d-orbital of surface iron.

The results of the weight loss study show that the formulation consisting of $250 \mathrm{ppm}$ of Amino benzoic acid has $93.71 \%$ IE in controlling corrosion of carbon steel in an aqueous solution containing SCP. Polarization study reveals that, formulation functions as an anodic inhibitor. AC impedance spectra reveal that a protective film is formed on the carbon steel surface. FTIR spectra reveal that the protective film consists of $\mathrm{Fe}^{2+}$ - Amino benzoic acid complex. To explain these facts the following mechanism of corrosion inhibition is proposed.

- When the solution containing SCP and $250 \mathrm{ppm}$ of Amino benzoic acid is prepared. Amino benzoic acid is ionized in this solution.

- When carbon steel is immersed in this solution, the ionized Amino benzoic acid goes to the surface of the carbon steel and is converted in to a $\mathrm{Fe}^{2+}-\mathrm{Amino}$ benzoic acid complex which is more stable.

- Amino benzoic acid $+\mathrm{Fe}^{2+} \rightarrow \mathrm{Fe}^{2+}-$ Amino benzoic 
acid

- Thus the protective film consists of $\mathrm{Fe}^{2+}-$ Amino benzoic acid complex. This is confirmed by FTIR spectra.

\section{CONCLUSION}

In the present study, the compound Amino benziocacid has been used to prevent the corrosion of carbon steel in an aqueous solution containing SCP The mechanistic aspects of corrosion inhibition are proposed based on the results obtained from the weight - loss method, the polarization study, AC impedance measurements, and surface examination techniques like FTIR spectroscopy. The rate of corrosion is decreased with the increasing addition of organic compound, probably due to progressive adsorption of the Amino benziocacid on the metal surface. The maximum inhibition efficiency was found to be $93.71 \%$.

The present study leads to the following conclusion

- The Amino benziocacid inhibitor exhibit good corrosion inhibition efficiency in controlling the corrosion of carbon steel in an aqueous solution containing SCP

- Polarization study shows that the effective Amino benziocacid systems function as anodic inhibitor controlling the anodic reaction predominantly.

- The weight loss technique shows the inhibition efficiency is $93.71 \%$.

- Electrochemical impedance measurements indicate that an increase the charge transfer resistance (Rt), increase the double layer capacitance (Cdl) and corrosion

- current (Icorr) values owing to the decreased thickness of adsorbed layer.

- FTIR spectra reveal that the protective film consists of $\mathrm{Fe}^{2+}$ Amino benzoic acid complex.

\section{REFERENCES}

Abuthahir, S.S., Nasser, A.J.A., Azar, M.M., Rashid, K.M. and Rajendran, S., (2016). Cobalt complex of 8-Hydroxyquinoline Derivative as Potential Corrosion Inhibitor for mild steel in aqueous sodium chloride solution. Int. J. Nano. Corr. Sci and Engg, 3(4).

Abuthahir, S.S., Nasser, A.J.A., Azar, M.M., Rashid, K.M. and Rajendran, S., (2016). Cobalt complex of 8-Hydroxyquinoline Derivative as Potential Corrosion Inhibitor for mild steel in aqueous sodium chloride solution. Int. J. Nano. Corr. Sci and Engg, 3(4).

Abuthahir, S.S., Abdul, N.A.J. and Rajendran, S., (2013). Highly effective inorganic corrosion inhibitor for mild steel in sodium chloride solution. European Chemical Bulletin, 2(12), pp.1041-1044.

Abuthahir, S.S., Nasser, A.J.A. and Rajendran, S., (2013). Electrochemical and surface analysis studies on corrosion inhibition od mild steel by 1-(8-Hydroxy Quinolin-2Ylmethyl) Thiourea. Europe Chemical Bulletin, 2(11), pp.932-935.
Abuthahir, S.S., Nasser, A.J.A., Azar, M.M., Rashid, K.M. and Rajendran, S., (2016). Cobalt complex of 8-Hydroxyquinoline Derivative as Potential Corrosion Inhibitor for mild steel in aqueous sodium chloride solution. Int. J. Nano. Corr. Sci and Engg, 3(4).

Agiladevi, S. and Rajendran, S., 2019. Electrochemical studies on the corrosion behavior of metals and alloys in simulated ringers solution. Rasayan Journal of Chemistry, 12(1), pp.22-31.

Behpour, M., Ghoreishi, S.M., Soltani, N., SalavatiNiasari, M., Hamadanian, M. and Gandomi, A., (2008). Electrochemical and theoretical investigation on the corrosion inhibition of mild steel by thiosalicylaldehyde derivatives in hydrochloric acid solution. Corrosion Science, 50(8), pp.2172-2181.

Ikhmal, W.M.K.W.M., Yasmin, M.Y.N., Maria, M.F.F., Syaizwadi, S.M., Rafizah, W.A.W., Sabri, M.G.M. and Zahid, B.M., (2020). Evaluating the performance of Andrographis paniculata leaves extract as additive for corrosion protection of stainless steel $316 \mathrm{~L}$ in seawater. Int. J. Corros. Scale Inhib, 9(1), pp.118-133.

J. Jayasundari, S. Rajendran, R. SayeeKannan, Y. Brightson Arul Jacob, Eur. Chem. Bull., 2585 (2013).

Johnsirani, V., Rajendran, S., Sathiyabama, J., Muthumegala, T.S., Krishnaveni, A. and Beevi, N.H., (2012). Inhibitive action of malachite green-Zn2+ system. Bulgarian Chemical Communications, 44(1), pp.41-51.

Kumar, V., (1998). Protection of steel reinforcement for concrete-A review. Corrosion Reviews, 16(4), pp.317358.

Labjar, N., Lebrini, M., Bentiss, F., Chihib, N.E., El Hajjaji, S. and Jama, C., (2010). Corrosion inhibition of carbon steel and antibacterial properties of aminotris(methylenephosphonic) acid. Materials Chemistry and Physics, 119(1-2), pp.330-336.

Lebrini, M., (2007). M. Lagrene e, H. Vezin, M. Traisnel, F. Bentiss. Corros. Sci, 49, p.2254.

Li, J.H., Zhao, B., Hu, J., Zhang, H., Dong, S.G., Du, R.G. and Lin, C.J., (2015). Corrosion inhibition effect of D-sodium gluconate on reinforcing steel in chloridecontaminated simulated concrete pore solution. Int. J. Electrochem. Sci, 10, pp.956-968.

Muralidharan, S., Babu, B.R., Iyer, S.V. and Rengamani, S., (1996). Influence of anions on the performance of isomers of aminobenzoic acid on the corrosion inhibition and hydrogen permeation through mild steel in acidic solutions. Journal of applied electrochemistry, 26(3), pp.291-296. Nagalakshmi, R., Nagarajan, L., Joseph Rathish, R., Santhana Prabha, S., Vijaya, N., Jeyasundari, J. and Rajendran, S., (2014). Corrosion Resistance Of SS3161 In Artificial Urine In Presence Of D-Glucose. Int. J. Nano. Corr. Sci. Engg, 1(1), pp.39-49.

Nasser, A.J.A. and Sathiq, M.A., (2016). N-[Morpholin- 
4-yl (phenyl) methyl] acetamide as corrosion inhibitor for mild steel in hydrochloric acid medium. Arabian Journal of Chemistry, 9, pp.S691-S698.

Nasser, A.J.A., (2005). Aliphatic sulfides: Effective corrosion inhibitors for mild steel in sulftiric acid. Bulletin of Electrochemistry, 21(7), pp.305-311.

Pandiarajan, M., Prabhakar, P. and Rajendran, S., 2012. Corrosion behavior of mild steel in simulated concrete pore solution prepared in rain water, well water and sea water. Eur. Chem. Bull, 1(7), pp.238-240.

Pandiarajan, M., Prabhakar, P. and Rajendran, S., (2013). Corrosion resistance of Mild steel in Simulated concrete Pore solution. Chem Sci Trans, 2(2), pp.605-613.

Sribharathy, V., Rajendran, S., Rengan, P. and Nagalakshmi, R., (2013). Corrosion inhibition by an aqueous extract of Aloe vera (L) Burm f.(Liliaceae). Eur. Chem. Bull, 2(7), pp.471-476.

Tiwari, A., Goyal, S., Luxami, V., Chakraborty, M. K., \& Gundlapalli, P. (2021). Evaluation of inhibition efficiency of generic compounds with additional heteroatom in simulated concrete pore solution and migration potential in concrete. Journal of Building Engineering, 43, 102490.
Thangavel, K., (2004). The threshold limit for chloride corrosion of reinforced concrete.

Vijaya, N., Regis, A.P.P., Rajendran, S., Pandiarajan, M. and Nagalakshmi, R., (2013). ROLE OF Zn 2 IN ENHANCING THE INHIBITION EFFICIENCY OF TRISODIUM CITRATE. amino acids, 5, p.6.

Vijaya, N., Regis, A.P.P., Rajendran, S., Pandiarajan, M. and Nagalakshmi, R., (2013). Role of Zn 2 in Enhancing the inhibition efficiency of trisodium citrate. amino acids, 5, p.6.

Yousif, Q.A. and Al-Zhara, A.A., (2016). Electrochemical methods, SEM-ED and AFM studies for assessing corrosion inhibition of carbon steel in acidic media. ARPN J Eng Appl Sci, 11, p.21.

Yang, H., Xiong, C., Liu, X., Liu, A., Li, T., Ding, R., ... \& Li, W. (2021). Application of layered double hydroxides (LDHs) in corrosion resistance of reinforced concretestate of the art. Construction and Building Materials, 307, 124991.

Zomorodian, A., Bagonyi, R., \& Al-Tabbaa, A. (2021). The efficiency of eco-friendly corrosion inhibitors in protecting steel reinforcement. Journal of Building Engineering, 38, 102171. 